\title{
INDUÇÃO DE MICRONÚCLEOS E TOXICIDADE POR EFLUENTE DOMÉSTICO EM DUAS POPULAÇÕES DE BATHYGOBIUS SOPORATOR (VALENCIENNES, 1837) (TELEOSTEI, GOBBIDAE) NO LITORAL DE SALVADOR (BA), BRASIL
}

\author{
GALINDO, T. ${ }^{* *} ;$ SILVA, E. ${ }^{2}$ \& ROSÁRIO, I. ${ }^{3}$ \\ 1 - Universidade do Aveiro, Portugal. \\ 2 - Universidade Federal da Bahia, Brasil. \\ 3 - Universidade Católica do Salvador, Brasil \\ * Contact author: pgalindo@ua.pt
}

\begin{abstract}
Galindo, T.; Silva, E. \& Rosário, I. 2012. Micronuclei induction and toxicity by domestic effluent in two populations of Bathygobius soporator (Valenciennes, 1837) (Teleostei, Gobbidae) on the coast of Salvador (BA), Brazil. Braz. J. Aquat. Sci. Technol. 16(1): 1-7. elSSN 1983-9057. Fish micronuclei tests were used to evaluate the potential of municipal wastewater sewage to cause genetic change in Bathygobius soporator. The levels of toxicity of municipal wastewater sewage were evaluated in populations of $B$. soporator originating from metal-contaminated and metal-free areas. Blood samples were taken from ten fish caught in sites with low anthropogenic influence to measure the levels of spontaneous micronucleated erythrocytes. An additional 30 fish specimens were captured to conduct laboratory testing. After a 30-day acclimation period, blood samples were collected under controlled conditions, while fish that were not sampled from blood were exposed to concentration of $10 \%$ of the urban effluents for 10 days. Acute toxicity experiments were also carried out at different concentrations $(0,1,3,7,10$, and $30 \%)$ of urban effluent for 48-h in using fish specimens of the two sampled populations of $B$. soporator. The results of this study showed that mortality was threefold higher for fish exposed to the urban effluents in the population of metal-free area compared with fish from the metal-contaminated area. There were micronucleus inductions in fish after 10 days of exposures to the urban effluents and significant differences $(p<0.01)$ after only 10 days when comparing to spontaneous micronucleus levels. We concluded that were microncleus inductions from urban effluents leading to higher mortality of individuals from the population of metal-free area, and this was higher than for individuals of the population exposed to metal contaminants.
\end{abstract}

Keywords: micronucleus, urban effluents, genotoxicity, toxicity, Bathygobius soporator.

\section{INTRODUÇÃO}

Dentre as principais fontes de poluição para os ecossistemas aquáticos no mundo destacam-se os efluentes domésticos e industriais, que tem recebido grande atenção por seus efeitos adversos nos organismos e ecossistema (Ohe et al., 2004). Os efluentes são misturas de natureza química complexa, produzidos por atividades humanas (Castillo et al., 2001). Nos Estados Unidos da América, a USEPA (U.S. Environmental Protection Agency) registrou que, no ano de 1994, 22.744 fábricas liberaram 432 toneladas de substâncias tóxicas no ambiente, das quais $2,9 \%$ foram despejadas em águas superficiais (Claxton et al., 1998). Muitos compostos, como metais e hidrocarbonetos policíclicos aromáticos, pesticidas, bifenis policlorados, dioxinas, furanos e aminas heterocíclicas presentes nesta mistura, são potencialmente tóxicos e mutagênicos (Jensen e Helz, 1998;
Rank e Nielsen, 1998; Cabrera et al., 1999; Grisolia e Starling, 2001; Cardozo et al., 2006). Atualmente, em muitos países, a avaliação de possíveis efeitos adversos destas descargas para o ecossistema é ineficiente, pois são priorizadas apenas análises químicas antes da disposição (Bobeldijk et al., 2002). Algumas fontes de químicos genotóxicos em extratos de águas superficiais e resíduos municipais incluem descargas sanitárias, pesticidas de gramados e jardins, combustão por produtos que entram no sistema municipal via escoamento superficial de estradas, áreas comerciais e industriais, descargas de hospitais e instituições de pesquisa que usam drogas antineoplásicas e genotóxicos experimentais (White e Rasmussen, 1998; Emmanuel et al., 2005).

O potencial de toxicidade destas misturas complexas ainda esta sobre discussão na literatura cientifica, porém, a maioria dos estudos foram realizados principalmente em bactérias (Claxton et al., 1998; Siddiqui e Ahmad, 2003), e outros organismos como 
leveduras (Schmitt et al., 2005), plantas (Smaka-Kincl et al., 1996; Grover e Kaur, 1999), anfíbios (Godet et al., 1996; Zoll-Moreux e Ferrier, 1999), células de mamíferos (Reifferscheid et al., 2008) e peixes (Dizer et al., 2002). O efeito mutagênico e carcinogênico de substâncias individuais que podem estar presentes nestas misturas são bem conhecidos (Cabrera et al., 1999). Substâncias contaminantes tóxicas liberadas na água podem não mostrar efeitos agudos em organismos expostos, porém, podem causar redução de sobrevivência, danos teciduais, danos genéticos de células somáticas e germinativas, acumulação de contaminantes persistentes (White e Rasmussen, 1998) e doenças como câncer e neoplasias (Myers et al., 1998).

Muitas espécies aquáticas são capazes de sobreviver em ambientes os quais contêm altos níveis de toxinas naturais ou poluentes antropogênicos, como locais sujeitos à descarga de efluentes (Bard, 2000). Os níveis de certos contaminantes nos tecidos destes organismos são mantidos abaixo daqueles observados no ambiente, sugerindo que esta resistência é mediada pelo fenômeno de resistência multixenobiótica, o qual é muito semelhante ao fenômeno de resistência multidrogas, primeiramente observado em linhagens de células tumorais resistentes a drogas anticâncer (van der Oost et al., 2003). O mecanismo de resistência multixenobiótica funciona como uma bomba dependente de energia que remove substâncias xenobióticas e endógenas das células, prevenindo sua acumulação e efeitos citotóxicos, sendo que, a proteína responsável por esta função de transporte é a P-glicoproteína transmembrana (Kurelec et al., 1995). Neste contexto, são objetivos deste trabalho avaliar a indução de micronúcleos pelo efluente doméstico na espécie de peixe marinho Bathygobius soporator e a toxicidade do efluente doméstico em duas populações desta espécie, uma em ambiente com presença de metais e outra livre de metais.

\section{MATERIAL E MÉTODOS}

O peixe marinho Bathygobius soporator (Valenciennes, 1837), utilizado neste estudo, é um teleósteo bentônico da família Gobiidae, encontrado em ilhas oceânicas, costões rochosos, recifes, estuários e em poças-de-maré na zona intertidal de praias rochosas (Akihito et al., 2000). Este último é um ambiente sob pressão antrópica, sujeito a despejo de efluentes domésticos, comum no litoral da cidade de Salvador-Ba.

Para determinar a contaminação do sedimento da zona intertidal do litoral da cidade de Salvador-Ba, por metais, foram coletadas amostras de sedimento superficial dos pontos P1 e P3 ( $5 \mathrm{~cm}$ de profundidade)

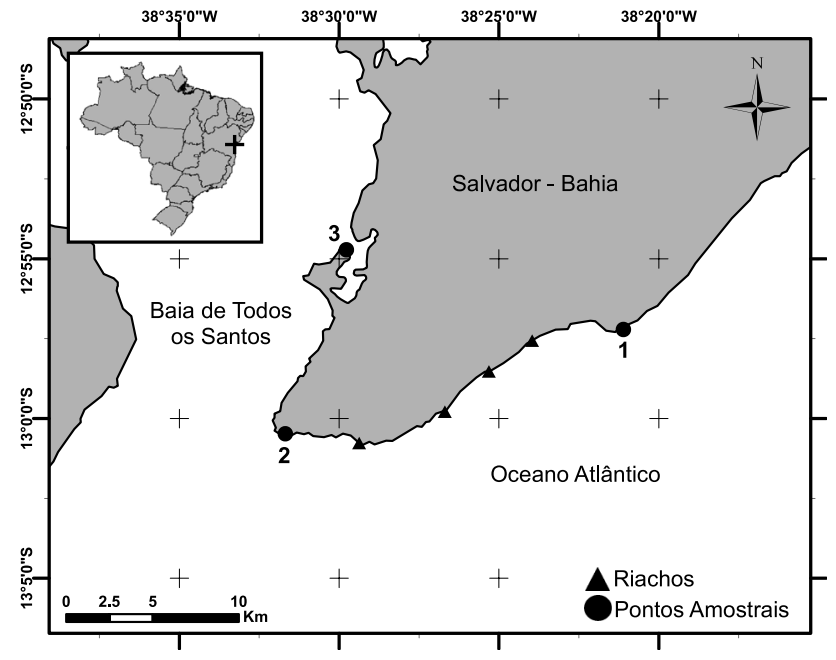

Figura 1 - Área de estudo do litoral de Salvador (Bahia, Brasil), mostrando os pontos amostrais e principais riachos.

(Figura 1), segundo Bicego et al. (2006), com espátula de aço inoxidável, estocados em vasilhas de alumínio (Gogou et al., 2000). Foi feita a extração segundo o método LEM-08 EPA 3051 (http://www.epa.gov). Esse método utiliza $0,5 \mathrm{~g}$ de amostra em ácido nítrico e água 1:1, digerido em forno de microondas (marca Provecto, modelo DGT 100 Plus). Após abertura, estas são filtradas em filtro quantitativo $(0,80 \mu \mathrm{M})$ e avolumadas em balão volumétrico $(50,0 \mathrm{~mL})$ com água deionizada. Posteriormente, foram armazenadas em frascos plásticos descontaminados para etapa de leitura no espectrômetro de absorção atômica (marca Varian, modelo SpectrAA 220 FS). Foram utilizados padrões Merck para a construção da curva de calibração do equipamento e 10 brancos para ser calculado o limite de detecção do método (LDM).

Para determinar a frequência basal de micronúcleos foram coletados aleatoriamente 20-25 espécimes de $B$. soporator nos pontos $\mathrm{P} 1$ e P3 em maio de 2007, sendo transportados imediatamente para o laboratório, onde foram mantidos com aeração constante. Em seguida, foram distribuídos em recipientes individuais de plástico de $500 \mathrm{~mL}$ com água do próprio ponto amostral, sorteados dez exemplares para coleta de sangue branquial por ponto amostral e, posteriormente, devolvidos ao hábitat. Foram realizados esfregaços de eritrócitos em lâminas (Bombail et al., 2001), que foram fixadas e coradas (Çavas et al., 2005; Galindo e Moreira, 2009). Foram contados 3000 eritrócitos (Metcalfe, 1988), em microscópio Zeiss em aumento de 1000 X. Micronúcleos são considerados todas as pequenas inclusões de material nuclear no citoplasma do eritrócito com tamanho variando de $1 / 3$ a 1/20 do núcleo principal, segundo os critérios para identificação dos micronúcleos (ver: Al-Sabti e Metcalfe, 1995; Çavas et al., 2005). 
Para os testes de toxicidade e genotoxicidade foi utilizado efluente doméstico da estação de condicionamento prévio da Embasa (Empresa Baiana de Águas e Saneamento S.A.), obtido em janeiro de 2008. Este corresponde ao efluente produzido na cidade de Salvador, que é lançado na região costeira sem tratamento prévio.

Para determinar o efeito genotóxico do efluente doméstico, em dezembro de 2007, amostras de sangue periférico foram coletadas de dez indivíduos de B. soporator coletados aleatoriamente no ponto 2 para a determinação da frequência basal de micronúcleos desta espécie neste ponto. Este ponto foi selecionado por ser o único com abundância suficiente de organismos para a realização do teste. Para avaliação de um possível efeito do estresse de confinamento sobre a frequência de micronúcleos, foram coletados 30 espécimes adicionais de $B$. soporator no ponto 2 . Estes indivíduos foram aclimatados, por 30 dias, em aquários (72L) contendo água do ponto 1 (considerado ponto referência) e alimentados uma vez ao dia com ração (Tetra Marine). Após o decorrer de 30 dias de aclimatação em laboratório, foi feita coleta de sangue periférico por sorteio de dez indivíduos para avaliação de um possível efeito do estresse de confinamento sobre a frequência de micronúcleos. Após a aclimatação foi iniciado a exposição dos organismos ao efluente domestico (concentração de $10 \%$ ), com coleta de sangue periférico de dez indivíduos sorteados nos momentos cinco e dez dias de exposição ao efluente. A exposição dos peixes foi feita em frascos plásticos de $500 \mathrm{~mL}$ com aeração constante e temperatura constante $\left(26 \pm 3^{\circ} \mathrm{C}\right)$. Foram mensurados $\mathrm{pH}$ (potenciômetro Misura Line), oxigênio dissolvido (oxímetro LT Lutron) e condutividade (condutivímetro Hanna Instruments, modelo HI 9030) em dias alternados no momento da exposição com os mesmos equipamentos descritos acima.

Para avaliação da toxicidade do efluente, foram coletados quarenta e oito espécimes por ponto amostral (P1 e P3) no litoral de Salvador (Ba), em janeiro de 2008. Os organismos foram levados ao laboratório e aclimatados em aquários ( $72 \mathrm{~L}$ ) com água do ponto 1 por $24 \mathrm{~h}$, em temperatura controlada $\left(26 \pm 3^{\circ} \mathrm{C}\right)$ e manuseados segundo Baumans (2005). Em cada ponto amostral foram expostos oito exemplares por diluição do efluente doméstico $0,1,3,7,10,30 \%$, diluído com água mar filtrada $(200 \mu \mathrm{m})$ do ponto 1 . Foram utilizados frascos plásticos (2-3 indivíduos por frasco) de $500 \mathrm{ml}$ com aeração constante. A contagem dos indivíduos mortos foi feita nos momentos $1 / 4,3 / 4$, 3, 9, 24 e $48 \mathrm{~h}$. Foram feitas mensurações de $\mathrm{pH}$, oxigênio dissolvido e condutividade, durante e no final do teste de exposição ao efluente, além da salinidade (salinômetro da marca Atago, modelo S/Mill).

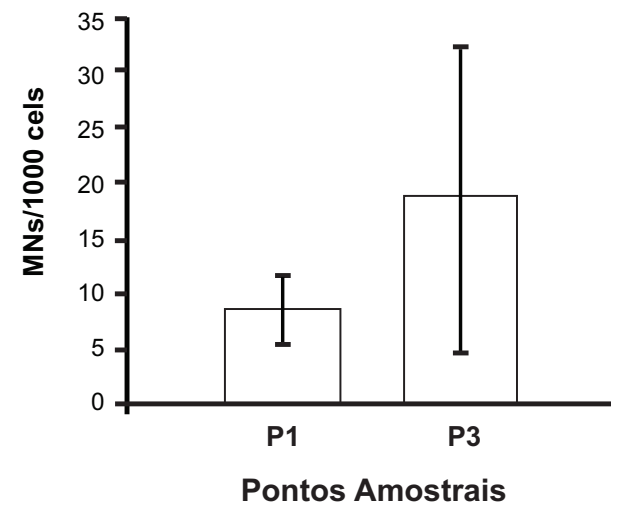

Figura 2 - Freqüência média de micronúcleos em $B$. soporator de dois pontos do litoral de Salvador (Ba), Brasil, 2007.

Foi aplicado um teste de análise de variância (ANOVA) de um fator, não paramétrica, após verificação da normalidade e homogeneidade dos dados da freqüência de micronúcleos, com os testes de Kolmogorov-Smirnov e Bartlet, respectivamente (Zar, 1996).

\section{RESULTADOS}

P1 apresentou menor frequência média de MNs (8,73/1000 cels) (Figura 2), metais abaixo do limite de detecção do método e mortalidade total de 19 indivíduos. P3 apresentou maior frequência média de MNs (18,53/1000 cels), presença de metais ( $\mathrm{Pb}$ 31,28 mg.kg-1, Hg 29,46 $\mu \mathrm{g} \cdot \mathrm{kg}-1$, Zn 25,53 mg.kg-1) (Tabela 1) e mortalidade três vezes menor (6) que P1(Tabela 2).

A salinidade variou de 25 a $33 \%$ nas diluições, porém, com menor valor (25\%) na diluição de $30 \%$. Não houve uma grande variação do $\mathrm{pH}$ do efluente nos diferentes tratamentos e momentos do teste. O oxigênio dissolvido teve pouca variação entre os tratamentos e etapas do teste, com menor valor nas diluições 10 e $30 \%$ no início da exposição (Tabela 3).

Não houve diferença estatisticamente significativa entre a freqüência média de micronúcleos do momento da coleta dos peixes (ponto 2) no ambiente e após trinta dias de aclimatação em aquários, com

Tabela 1 - Metais em sedimento de dois pontos amostrais do litoral de Salvador (Ba), Brasil, 2007.

\begin{tabular}{llcc}
\hline \hline Metais $\mathbf{~ m g} / \mathbf{k g}^{-1}$ & LDM & \multicolumn{1}{c}{$\mathbf{1}$} & $\mathbf{3}$ \\
\hline $\mathrm{Pb}$ & 10,053 & $<$ LDM & 31,284 \\
$\mathrm{Hg}(\mu \mathrm{g} / \mathrm{kg}-1)$ & 0,001 & $<$ LDM & 29,460 \\
$\mathrm{Zn}$ & 2,761 & $<$ LDM & 23,538 \\
$\mathrm{Cr}$ & 6,07 & $<$ LDM & $<$ LDM \\
$\mathrm{Mn}$ & 7,28 & 16,263 & 25,974 \\
$\mathrm{Cd}$ & 0,892 & $<$ LDM & $<$ LDM \\
\hline \hline
\end{tabular}


Tabela 2 - Mortalidade em adultos (após 48h) de B. soporator $(n=8)$ coletados em dois pontos do litoral de Salvador-Ba, expostos a diferentes diluições de efluente doméstico.

\begin{tabular}{lcc}
\hline \hline Diluição (\%) & Ponto 1 & Ponto 3 \\
\hline 0 & 1 & 0 \\
1 & 2 & 2 \\
3 & 5 & 2 \\
7 & 4 & 0 \\
10 & 2 & 0 \\
30 & 5 & 2 \\
Mortalidade Total & 19 & 6 \\
\hline \hline
\end{tabular}

pequeno decréscimo no último. Houve indução de micronúcleos em $B$. soporator exposto ao efluente doméstico a $10 \%$ nos momentos de exposição cinco e dez dias, comparados à freqüência basal, porém houve diferença significativa $(p<0,005)$ apenas no último (Figura 3).

Não houve grande variação do $\mathrm{pH}$ nos aquários de aclimatação e no efluente doméstico no teste de exposição de dez dias. A média de oxigênio dissolvido e condutividade foram mais elevadas nos aquários de aclimatação em relação aos efluentes domésticos diluídos a 10\% (Tabela 4).

\section{DISCUSSÃO}

Embora, as análises químicas sejam o método primário comumente utilizado para avaliar o potencial de toxicidade de efluentes devido à complexidade química (Cardozo et al., 2006), Castillo et al. (2001) ressaltam as limitações desta extrapolação, portanto nenhum programa de biomonitoramento deve ser baseado unicamente em análise química, a qual não fornece informações suficientes para a análise de risco ecológico. Em contraste, os bioensaios demonstram os efeitos em análises de toxicidade de misturas complexas, sem um conhecimento a priori da composição química da mistura. Claxton et al. (1998) argumentam que, a utilização conjunta de análises químicas e bioenssaios aumentam a confiabilidade destes testes, permitindo ainda o isolamento e identificação de frações que contêm atividade genotóxica.

O presente estudo mostrou que a população de $B$. soporator do ponto livre de contaminação (P1) teve mortalidade três vezes mais elevada em comparação ao ponto contaminado com metais (P3). Estudos demonstram que espécies de ambientes prístinos são mais susceptíveis a efeitos adversos que espécies de ambientes impactados em casos de acidentes como derramamentos de óleos (Bard, 2000), comuns em locais de atividades de petróleo. A resistência multixenobiótica em espécies expostas é explicada pela superexpressão da P-glicoproteína transmembrana que previne a acumulação de drogas citotóxicas em células resistentes, além do sistema de detoxificação

Tabela 3 - Variação do pH, oxigênio dissolvido e condutividade de diferentes diluições de efluente doméstico na exposição de $B$. soporator de dois pontos do litoral da cidade de Salvador (BA).

\begin{tabular}{lccccccccc}
\hline \hline & \multicolumn{3}{c}{ Início } & \multicolumn{4}{c}{$9 \mathrm{~h}$} & \multicolumn{3}{c}{$48 \mathrm{~h}$} \\
\cline { 2 - 9 } Ponto 3 & $\begin{array}{c}\mathrm{pH} \\
(\mathrm{mg} / \mathrm{L})\end{array}$ & $\begin{array}{c}\text { Cond } \\
(\mathrm{mS} / \mathrm{cm})\end{array}$ & $\begin{array}{c}\mathrm{pH} \\
(\mathrm{mg} / \mathrm{L})\end{array}$ & $\begin{array}{c}\text { Cond } \\
(\mathrm{mS} / \mathrm{cm})\end{array}$ & $\begin{array}{c}\mathrm{pH} \\
(\mathrm{mg} / \mathrm{L})\end{array}$ & $\begin{array}{c}\text { Cond } \\
(\mathrm{mS} / \mathrm{cm})\end{array}$ \\
\cline { 2 - 9 } $0 \%$ & 6,59 & 6,5 & 47,3 & 6,9 & 6,2 & 47,1 & 6,4 & 4,2 & 52 \\
$1 \%$ & 7,56 & 5,5 & 45,6 & 5,5 & 5,6 & 45,5 & 7,0 & 4,0 & 45,7 \\
$3 \%$ & 7,4 & 5,2 & 51,1 & 4,6 & 6,0 & 45,6 & 5,3 & 3,7 & 45,7 \\
$7 \%$ & 7,4 & 5,1 & 32,5 & 5,3 & 4,1 & 47,6 & 6,0 & 3,8 & 43,1 \\
$10 \%$ & 6,3 & 4,5 & 41,9 & 6,8 & 3,8 & 42,4 & 6,2 & 4,0 & 47,4 \\
$30 \%$ & 4,22 & 3,8 & 43,2 & 6,2 & 5,2 & 45,8 & 6,8 & 4,2 & 45,9 \\
Média & 7 & 5,1 & 43,6 & 6,0 & 5,0 & 45,7 & 6,28 & 4,0 & 46,6 \\
Ponto 1 & & & & & & & & & \\
$0 \%$ & 8,5 & 9,2 & 51,8 & 8,5 & 8,3 & 46,3 & 7,9 & 5,2 & 46,5 \\
$1 \%$ & 8,5 & 9,0 & 48,8 & 8,5 & 8,0 & 45,4 & 8,1 & 5,4 & 47,3 \\
$3 \%$ & 8,6 & 8,9 & 48,5 & 8,3 & 8,3 & 47,4 & 8,2 & 5,7 & 44,9 \\
$7 \%$ & 8,4 & 8,8 & 46,3 & 8,5 & 8,5 & 43,4 & 8,2 & 5,8 & 38,2 \\
$10 \%$ & 8,2 & 9,0 & 41,1 & 8,5 & 8,6 & 41,9 & 8,4 & 6,4 & 37,1 \\
$30 \%$ & 7,9 & 9,1 & 38,7 & 8,5 & 8,5 & 36,1 & 8,3 & 6,5 & 36,1 \\
Média & 8,4 & 9,0 & 45,9 & 8,5 & 8,4 & 43,4 & 8,2 & 5,8 & 41,7 \\
\hline \hline
\end{tabular}




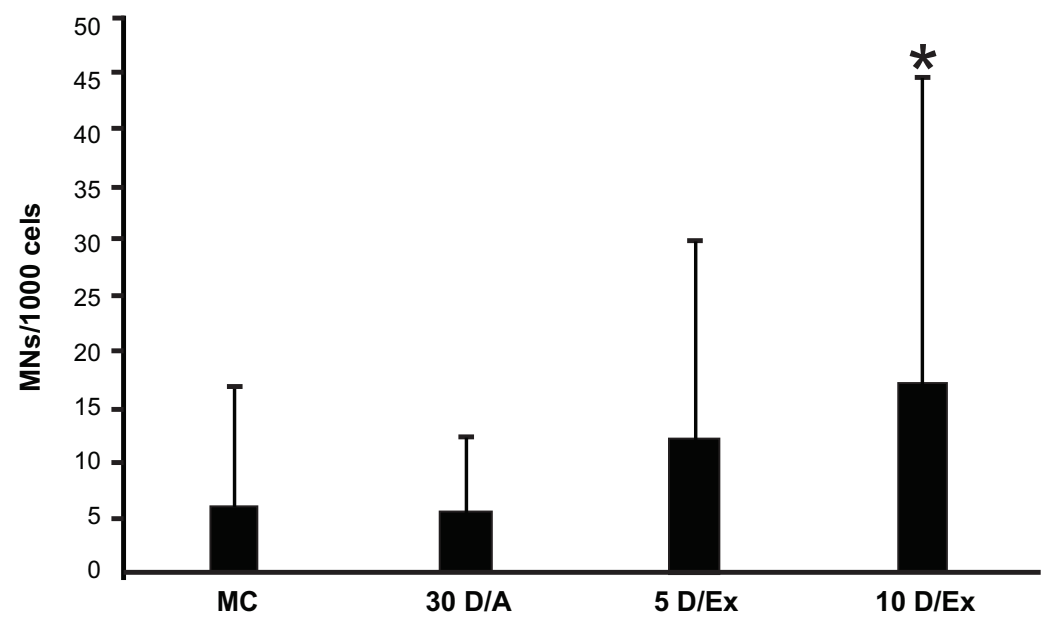

Figura 3 - Freqüência média de micronúcleos em eritrócitos de B. soporator. MC: momento de coleta no ambiente; 30 D/A: após 30 dias de aclimatação em laboratório; 5 D/Ex: cinco dias de exposição ao efluente doméstico (10\%); 10 D/Ex: dez dias de exposição ao efluente doméstico (10\%). ANOVA de um fator, $(\alpha=0,05) .{ }^{*} p<0,05$.

de fase I, II e III (Bard, 2000; van der Oost et al., 2003). Este mecanismo de resistência foi encontrado em diversos animais marinhos e representa o mecanismo de defesa geral de proteção contra toxinas endógenas e ambientais (Kurelec et al., 1995; Moreau et al., 2008). Processos naturais também estão relacionados ao mecanismo de resistência, como mudança na diversidade genética de uma população exposta através da deriva genética randômica, fluxo gênico após redução drástica no tamanho populacional e seleção de um caráter após seleção dirigida causadas por estresse ambiental de poluentes (Knapen et al., 2004; Medina et al., 2007), que explicariam mudanças rápidas na diversidade genética das populações expostas.

Neste estudo foi evidenciado efeito genotóxico pela indução de micronúcleos em eritrócitos na espécie $B$. soporator do ponto 2 exposta a efluente doméstico por 5 e 10 dias. Diversos autores têm demonstrado o potencial mutagênico em misturas complexas de efluentes domésticos e industriais com testes de genotoxicidade (Cabrera et al., 1999; Cas- tillo et al., 2001; Békaert et al., 2002). Estudos para avaliar o potencial mutagênico de efluentes relatado por Claxton et al. (1998), apontam que, 60\% emprega o teste com Salmonella, pela facilidade e baixo custo, porém, atualmente, outros organismos estão sendo empregados como sentinela, dentre eles os peixes (Al-Sabti e Metcalfe, 1995; van der Oost et al, 2003). Os peixes de água doce são os mais utilizados no monitoramento devido à facilidade de manutenção em laboratório de muitas espécies, acessibilidade aos ambientes e facilidade de coleta, mas estes ambientes representam uma pequena porcentagem dos ambientes aquáticos no mundo em comparação aos ambientes marinhos. Grisolia et al. (2005) avaliaram a exposição de duas espécies de peixe de água doce ao efluente doméstico após o processo de tratamento de três etapas, e não encontrou indução de micronúcleos, porém, houve diminuição do índice mitótico em raiz de Allium cepa na exposição do efluente bruto, e no tratamento secundário e terciário. Em outro estudo, Grisolia e Starling (2001) demonstraram diferenças

Tabela 4 - Média de oxigênio dissolvido, pH e condutividade em dias alternados de aquários de aclimatação e efluente (10\%) em teste de exposição de $B$. soporator por 10 dias.

\begin{tabular}{lccc}
\hline \hline & $\mathbf{p H}$ & OD $(\mathbf{m g} / \mathbf{L})$ & Cond. $(\boldsymbol{\mu S} / \mathbf{c m})$ \\
\hline Efluente 1 & 6,89 & 3,85 & 66,71 \\
Efluente 2 & 7,32 & 3,20 & 64,46 \\
Efluente 3 & 7,40 & 4,33 & 61,71 \\
Efluente 4 & 6,95 & 3,30 & 65,30 \\
Efluente 5 & 7,40 & 3,70 & 64,72 \\
Aquário 1 & 7,34 & 5,35 & 76,30 \\
Aquário 2 & 7,02 & 5,00 & 76,75 \\
Aquário 3 & 7,18 & 5,18 & 76,53 \\
Aquário 4 & 7,10 & 5,09 & 76,64 \\
Aquário 5 & 7,38 & 4,00 & 69,85 \\
\hline \hline
\end{tabular}


não significativas de micronúcleos em pontos do Lago Paranoá (DF), sujeitos à descarga de efluentes em três espécies de água doce.

Como conclusão este estudo demonstra que a população de $B$. soporator do ponto livre de contaminação $(\mathrm{P} 1)$ teve mortalidade três vezes mais elevada em comparação ao ponto com metais (P3). O teste de micronúcleos em eritrócitos do peixe marinho $B$. soporator demonstrou indução de micronúcleos em peixes do ponto 2 expostos ao efluente doméstico após cinco e dez dias. Este trabalho, em acordo com outros estudos já citados, demonstra que houve efeito genotóxico na exposição ao efluente doméstico, com indução três vezes superior em relação à freqüência basal.

\section{AGRADECIMENTOS}

Agradecemos ao CNPq (Conselho Nacional de Desenvolvimento Científico e Tecnológico), a Capes (Coordenação de Aperfeiçoamento de Pessoal de Nível Superior). Cíntia e Ubiratam Outeiro.

\section{REFERÊNCIAS BIBLIOGRÁFIAS}

Akihito; Iwata, A.; Kobayashi, T.; Ikeo, K.; Imanishi, T.; Ono, H.; Umehara, Y.; Hamamatsu, C.; Sugiyama, K.; Ikeda, Y.; Sakamoto, K.; Fumihito, A.; Ohno, S. \& Gojobori, T. 2000. Evolutionary aspects of gobioid fishes based upon a phylogenetic analysis of mitochondrial cytochrome b genes. Gene 259: 5-15.

Al-Sabti, K. \& Metcalfe, C.D. 1995. Fish micronuclei for assessing genotoxicity in water. Gen. Toxicol. 343: 121-135.

Bard, S.M. 2000. Multixenobiotic resistance as a cellular defense mechanism in aquatic organisms. Aqua. Toxicol. 48: 357-389.

Baumans, V. 2005. Science-based assessment of animal welfare: laboratory animals. Rev. sci. tech., Off. int. épizoot. 24: 503-514.

Békaert, C.; Ferrier, V.; Marty, J.; Pfohl-Leszkowicz, A.; Bispo, A.; Jourdain, M.J.; Jauzein, M.; Lambolez-Michel, L. \& Billard, H. 2002. Evaluation of toxic and genotoxic potential of stabilized industrial waste and contaminated soils. Waste Manag. 22: 241-247.

Bicego, M.C.; Taniguchi, S.; Yogui, G.T.; Montone, R.C.; Silva, D.A.M.; Lourenço, R.A.; Martins, C.C.; Sasaki, S.T.; Pellizari, V.H. \& Weber, R.R. 2006. Assessment of contamination by polychlorinated biphenyls and aliphatic and aromatic hydrocarbons in sediments of the Santos and SãoVicente Estu- ary System, São Paulo, Brazil. Mar. Pollut. Bull. 52: 1784-1832.

Bobeldijk, I.; Stoks, P.G.M.; Vissers, J.P.C.; Emke, E.; van Leerdama, J.A.; Muilwijk, B.; Berbee, R. \& Noij, T.H.A. 2002. Surface and wastewater quality monitoring: combination of liquid chromatography with (geno)toxicity detection, diode array detection and tandem mass spectrometry for identification of pollutants. J. Chromat. 970: 167-181.

Bombail, V.; Aw, D.; Gordon, E. \& Batty, J. 2001. Application of the comet and micronucleus assays to butterfish (Pholis gunnellus) erythrocytes from the Firth of Forth, Scotland. Chemosphere 44: 383-392.

Cabrera, G.L.; Rodriguez, D.M.G. \& Maruri, A.B. 1999. Genotoxicity of the extracts from the compost of the organic and the total municipal garbage using three plant bioassays. Mutat. Res. 426: 201-206.

Cardozo, T.R.; Rosa, D.P.; Feiden, I.R.; Rocha, J.A.V.; Oliveira, N.C.D.; Pereira, T.S.; Pastoriza, T.F.; Marques, D.M.; Lemosa, C.T.; Terra, N.R. \& Vargas, V.M.F. 2006. Genotoxicity and toxicity assessment in urban hydrographic basins. Mutat. Res. 603: 83-96.

Castillo, M.; Alonso, M.C.; Riu, J.; Reinke, M.; Klöter, G.; Dizer, H.; Fischer, B.; Hansen, P.D. \& Barceló, D. 2001. Identification of cytotoxic compounds in European wastewaters during a field experiment. Anal. Chim. Acta 426: 265-277.

Çavas, T.; Garanko, N.N. \& Arkhipchuk, V.V. 2005. Induction of micronuclei and binuclei in blood, gill and liver cells of fishes subchronically exposed to cadmium chlorid and copper sulphate. Food Chem Toxicol 43: 569-574.

Claxton, L.D.; Houk, V.S. \& Hughes, T.J. 1998. Genotoxicity of industrial wastes and effluents. Mutat. Res. 410, 237-243.

Dizer, H.; Wittekindt, E.; Fischer, B. \& Hansen, P.D. 2002. The citotoxic and gentotoxic potential of surface water and wastewater effluents as determined by bioluminescence, umu-assays and selected biomarkers. Chemosphere 46: 225-233.

Emmanuel, E.; Perrodin, Y.; Keck, G.; Blanchard, J.M. \& Vermande, P. 2005. Ecotoxicological risk assessment of hospital wastewater: a proposed framework for raw effluents discharging into urban sewer network. J. Hazard. Mat. 117: 1-11.

Galindo, T.P.S; Moreira, L.M. 2009. Evaluation of genotoxicity using the micronucleus assay and nuclear abnormalities in the tropical sea fish Bathygobius soporator (Valenciennes, 1837) (Teleostei, Gobiidae). Genet. Mol. Biol. 32: 394-398.

Godet, F.; Babut, M.; Burnel, D.; Veber, A.M. \& Vasseur, P. 1996. The genotoxicity of iron and chromium in electroplating effluents. Mutat. Res. 370: 19-28. 
Gogou, A.; Bouloubassi, I. \& Stephanou, E.G. 2000. Marine organic geochemistry of the Eastern Mediterranean: Aliphatic and polyaromatic hydrocarbons in Cretan Sea Surficial sediments. Mar. Chem. 68 (4): 265-282.

Grisolia, C.K. \& Starling, F.L.R.M. 2001. Micronuclei monitoring of fishes from Lake Paranoá, under influence of sewage treatment plant discharges. Mutat. Res. 491: 39-44.

Grisolia, C.K.; Oliveira, A.B.B.; Bonfim, H. \& KlautauGuimarães, N. 2005. Genotoxicity evaluation of domestic sewage in a municipal wastewater treatment plant. Genet. Mol. Biol. 28: 334-338.

Grover, I.S. \& Kaur, S. 1999. Genotoxicity of wastewater samples from sewage and industrial effluent detected by the Allium root anaphase aberration and micronucleus assays. Mutat. Res. 426: 183-188.

Jensen, J.S. \& Helz, G.R. 1998. Dechlorination kinetics at alkaline $\mathrm{pH}$ of $\mathrm{N}$-chloropiperidine, a genotoxin in chlorinated municipal wastewater. Wat. Res. 32: 2615-2620.

Knapen, D.; Bervoets, L.; Verheyen, E. \& Blust, R. 2004. Resistance to water pollution in natural gudgeon (Gobio gobio) populations may be due to genetic adaptation. Aqua. Toxicol. 67: 155-165.

Kurelec, B.; Piecevic, B. \& Miiller, W.E.G. 1995. Determination of pollutants with multixenobiotic- resistance inhibiting properties. Mar. Environ. Res. 39: 261-265.

Medina, M.H.; Correa, J.A. \& Barata, C. 2007. Microevolution due to pollution: Possible consequences for ecosystem responses to toxic stress. Chemosphere 67: 2105-2114.

Metcalfe, C.D. 1988. Induction of micronuclei and nuclear abnormalities in the erythrocytes of mudminnows (Ulbra limi) and brown bullheads (Ictalurus nebulosus). Environ. Cont. Toxicol. 40: 498-495.

Moreau, X.; Saez, G.; Thiéry, A.; Clot-Faybesse, O.; Guiraudie-Capraz, G.; Bienboire-Frosini, C.; Martin, C. \& De Jong, L. 2008. Elisa detection of multixenobiotic resistance transporter induction in indigenous freshwater chironomidae larvae (diptera): a biomarker calibration step for in situ monitoring of xenobiotic exposure. Environ. Poll. 153: 1-8.

Myers, M.S.; Johnson, L.L.; Horn, T.; Collier, T.K.; Stein, J.E. \& Varanasi, U. 1998. Toxicopathic hepatic lesions in subadult english sole (Pleuronectes vetulus) from Puget Sound, Washington, USA: relationships with other biomarkers of contaminant exposure. Mar. Environ. Res. 45: 41-61.

Ohe, T.; Watanabe, T. \& Wakabayashi, K. 2004. Mutagens in surface waters: a review. Mutat. Res. 567, 109-149.

Rank, J. \& Nielsen, M.H. 1998. Genotoxicity testing of wastewater sludge using the Allium cepa anaphase-telophase chromosome aberration assay. Mutat. Res. 418: 113-119.

Reifferscheid, G.; Ziemann, C.; Fieblinger, D.; Dill, F.; Gminski, R.; Grummt, H.G.; Hafner, C.; Hollert, H.; Kunz, Z.; Rodrigo, G.; Stopper, H. \& Selke, D. 2008. Measurement of genotoxicity in wastewater samples with the in vitro micronucleus test - Results of a round-robin study in the context of standardisation according to ISO. Mutat. Res. 649: 15-27.

Schmitt, M.; Gellert, G. \& Lichtenberg-Fraté, H. 2005. The toxic potential of an industrial effluent determined with the Saccharomyces cerevisiae-based assay. Wat. Res. 39: 3211-3218.

Siddiqui, A.H. \& Ahmad, M. 2003. The Salmonella mutagenicity of industrial, surface and ground water samples of Aligarh region of India. Mutat. Res. 541, 21-29.

Smaka-Kincl, V.; Stegnar, P.; Lovka, M. \& Toman, M.J. 1996. The evaluation of waste, surface and ground water quality using the Allium test procedure. Mutat. Res. 368: 171-179.

van der Oost, R.; Beyer, J. \& Vermeulen, N.P.E. 2003. Fish bioaccumulation and biomarkers in environmental risk assessment: a review. Environ. Toxicol. Pharmacol. 13: 57-149.

White, P.A. \& Rasmussen, J.P. 1998. The genotoxic hazards of domestic wastes in surface waters. Mutat. Res. 410: 223-236.

Zar, J.H. 1996. Biostatistical Analysis. $3^{\circ}$ Edition. Prentice-Hall Int, Upper Saddle River, 662p.

Zoll-Moreux, C. \& Ferrier, V. 1999. The jaylet test (newt micronucleus test) and the micronucleus test in xenopus: two in vivo tests on amphibia evaluation of the genotoxicity of five environmental pollutants and of five effluents. Wat. Res. 33: 2301-2314.

Submetido: Outubro/2010 Revisado: Dezembro/2010 Aceito: Abril/2011 